\title{
CD133/CD15 defines distinct cell subpopulations with differential in vitro clonogenic activity and stem cell-related gene expression profile in in vitro propagated glioblastoma multiforme-derived cell line with a PNET-like component
}

\author{
Ulf D. Kahlert ${ }^{1, \star}$, Noemi O. Bender ${ }^{2, \star}$, Donata Maciaczyk ${ }^{1}$, Tomasz Bogiel ${ }^{1,3}$, Eli E. Bar ${ }^{4}$, Charles G. Eberhart \\ Guido Nikkhah', Jaroslaw Maciaczyk ${ }^{6}$ \\ *Authors contributed equally to this work
}

\begin{abstract}
1Division of Stereotactic Neurosurgery, Department of General Neurosurgery, University Medical Center Freiburg, Freiburg, Germany, 2Deutsches Krebsforschungszentrum, Heidelberg, Germany, ${ }^{3}$ Laboratory of Clinical Genetics, Department of Pathomorphology, $10^{\text {th }}$ Military Hospital, Bydgoszcz, Poland, ${ }^{4}$ Department of Neurological Surgery, Robbins Research Building, Case Western Reserve University, Cleveland, OH, USA, ${ }^{5}$ Department of Pathology, Johns Hopkins Medical Institutions, Baltimore, MD, USA, ${ }^{6}$ Department of General Neurosurgery, University Medical Center Freiburg, Freiburg, Germany
\end{abstract}

\begin{abstract}
Glioblastoma multiforme (GBM), as many other solid tumours, contains a subpopulation of cells termed cancer stemlike cells responsible for the initiation and propagation of tumour growth. However, a unique immunophenotype/surface antigen composition for the clear identification of brain tumour stem cells (BTSC) has not yet been found. Here we report a novel code of cell surface markers for the identification of different cell subpopulations in neurospheres derived from a GBM with a primitive neuroectodermal tumour (PNET)-like component (GBM-PNET). These subgroups differ in their CD133/CD15 expression pattern and resemble cells with different stem-like genotype and developmental pathway activation levels. Strikingly, clonogenic analysis of cultures differentially expressing the investigated markers enabled the identification of distinct subpopulations of cells endowed with stem cell characteristics. High clonogenicity could be found in CD133- $/ C D 15^{-}$and $C D 133^{+} / C D 15^{+}$but not in CD133- $/ C D 15^{+}$cells. Moreover, cell subpopulations with pronounced clonogenic growth were characterized by high expression of stem cell-related genes. Interestingly, these observations were unique for GBM-PNET and differed from ordinary GBM cultures derived from tumours lacking a PNET component. This work elucidates the complex molecular heterogeneity of in vitro propagated glioblastoma-derived cells and potentially contributes to the development of novel diagnostic modalities aiming at the identification of the brain tumour stem-like cell population in a subgroup of GBMs.
\end{abstract}

Key words: GBM, PNET, brain tumour stem-like cell, CD133, clonogenicity.

\footnotetext{
Communicating author:

Jaroslaw Maciaczyk, MD, Department of General Neurosurgery, University Freiburg Medical Center, Germany,

e-mail: jaroslaw.maciaczyk@uniklinik-freiburg.de
} 


\section{Introduction}

Glioblastoma multiforme (GBM) belongs to the most frequent malignant glial brain tumours in adult humans. Despite the intensive multimodal treatment including surgery, followed by the combination of radio- and chemotherapy, the majority of patients die within 1 to 2 years of diagnosis due to tumour progression [27].

In a small subpopulation of GBMs, areas with primitive neuroectodermal tumour (PNET)-like differentiation occur (GBM-PNET, i.e. $[19,29,37])$. PNET - an embryonic malignant, non-cerebellar neural neoplasm with medulloblastoma-like histology phenotypically recapitulates the primitive developmental stages of the central nervous system [27]. On a molecular level GBMPNET generally shows C-MYC-gene amplification, and can reproduce PNET-like clinical behaviour, including cerebrospinal fluid dissemination and responsiveness to platinum-based chemotherapeutic regimens [37]. Recent clinicopathologic and genetic data suggest a stepwise development of GBM-PNET originating from an underlying high-grade glioma with secondary development of PNET-like foci [37].

As many other solid tumours, malignant gliomas including GBM and GBM-PNET, contain a small population of cells with stem cell-like properties termed brain tumour stem-like cells (BTSC), which are presumably responsible for tumour initiation and relapse following therapy $[9,48]$. These cells are characterized by karyotypic or genetic alterations, aberrant differentiation properties and demonstrate extensive in vitro or in vivo self-renewal in addition to the ability to generate non-tumorigenic end cells [9]. Interestingly, the concept of misregulated differentiation processes of putative stem-like cells might be an explanation for multi-lineage maturation within one tumour as is the case in GBM-PNETs, containing both astrocytic and neuronal progeny as well as imperfect neural or oligodendroglial differentiation to be found in GBMs [50].

Despite extensive research over the last decade [26] the unequivocal identification of BTSC remains problematic. Parallel to functional assays, investigating biological properties attributed to the stem cell population including in vitro and in vivo tumour forming capacity as well as staining methods related to stemcell specific enzyme activity (side population [7], aldehyde dehydroxylase activity - AldeFluor [4]), several surface bound molecules have been proved to be enriched in this cell subpopulation. The most investigated and still regarded as the bona fide brain tumour stem cell marker is CD133 (PROM1) [3,44] belonging to the pentaspan, transmembrane family of glycoproteins (for review see [31]) and being expressed by numerous tissue-specific stem cells including neural stem cells [46]. Its role as a molecule enabling the prospective isolation of cells with stem-cell characteristics, such as the capacity to generate tumours in immunocompromised rodents [44] as well as being responsible for the resistance to radiation and chemotherapy $[3,20]$ from malignant brain tumours has recently been questioned with reports showing tumour initiating properties of CD133- glioblastoma-derived cells [10,21,24]. Therefore, many other molecules have been investigated as potential ultimate or combinatory markers of brain tumour stem cells. These include CD15 (also called stage-specific embryonic antigen 1 present in many pluripotent stem cell populations including neural stem cells [39] as well as in paediatric brain tumours [40].

In the current study, we analysed the expression of CD133/CD15 in GBM-PNET-derived neurospheres and could identify several cell populations with different in vitro tumour initiating properties and distinct regulation of stem cell-related gene expression, suggesting the existence of a hierarchy of stem cells in this particular malignant brain tumour type. These findings were somewhat different from those in GBM neurospheres derived from tumours, lacking a primitive neuroectodermal component, and may lead to the development of novel diagnostic approaches enabling the prospective identification and isolation of a putative stem-like cell population from malignant glial tumours with PNET-like foci, for clinical and research purposes.

\section{Material and methods \\ Establishment of primary cell culture from a tumour specimen}

All procedures described were approved by the local ethical committee of the Johns Hopkins Medical Institutions, Baltimore, USA in accordance with the local law. The GBM10 cell line was derived from a sample collected following surgical resection under institutional review board-approved protocols. The diagnosis of the malignant brain tumour has been confirmed by the neuropathological examination in accordance with WHO established guidelines.

This cell line has been propagated in free-floating culture system containing a significant proportion of $\mathrm{CD}_{133^{+}}$putative BTSC with clonogenic potential and 
in vivo tumour growth following implantation into immunoincompetent rodent recipients as previously described [5]. In brief, the tumour tissue was dissected mechanically, using sterile scalpels, digested with TrypLE Express (Life Technologies) for 15 to $30 \mathrm{~min}$ at $37^{\circ} \mathrm{C}$, to digest extracellular matrix, then centrifuged, resuspended in DNase $(0.1 \%$, GE Healthcare) and incubated for $2-3 \mathrm{~min}$ at $37^{\circ} \mathrm{C}$. Afterwards, the tissue was triturated to single cell suspension. Before cell plating the cell suspension was filtered through a $40 \mu \mathrm{m}$ cell strainer to separate tissue remnants from the cells.

Furthermore, established primary GBM-derived cell lines without PNET-compartment were tested. For the purpose of this report we present the data concerning the representative, well-characterized cell line HSR-GBM1 obtained courtesy of A. Vescovi, Stemgen S.p.A., Milan, Italy [4].

\section{Cell culture}

The cells were cultured in suspension conditions as described previously $[22,28]$ in Dulbecco's modified Eagle's medium (DMEM)/F12 (3: 1) medium supplemented with B27 (Life Technologies), 20 ng/ml bFGF, $20 \mathrm{ng} / \mathrm{ml}$ recombinant hEGF (both R\&D Systems), penicillin/streptomycin (Life Technologies), and $5 \mu \mathrm{g} / \mathrm{ml}$ heparin (Sigma-Aldrich). The tumour spheres were passaged once every week, as described above, applying enzymatic and mechanic dissociation. Cell culture medium was refreshed twice per week to guarantee constant supply of required growth factors and nutrients.

\section{Flow cytometry}

All antigen labelling steps were performed on ice. After harvesting and washing once with PBS, the cells were resuspended in an appropriate amount of $1 \times$ PBS $+2 \% \mathrm{FCS}+0.1 \% \mathrm{NaN}_{3}$. For simultaneous cell surface immunostaining for CD133 and CD15, $5 \times 10^{5}$ cells were retrieved from a single-cell suspension, and labelled with anti-CD133/1-Phycoerithrin (PE) antibody (\#130080-801, Miltenyi Biotec) and anti-CD15-Fluorescein isothiocyanate (FITC) antibody (\# 560997, BD Pharmingen) according to manufacturer's instructions.

The antibody solution consisted of antigen specific antibody (each 1 : 11 volume dilution) in $1 \times$ PBS $+2 \%$ $\mathrm{FCS}+0.1 \% \mathrm{NaN}_{3}$. All (+)-fractions were gated using respective isotype controls (for CD133-PE: anti mouse IgG2b-PE, \# 130-092-215, Miltenyi Biotec; for CD15-FITC: FITC Mouse IgG1, \# 130-092-213, Miltenyi Biotec).
FACS-analyses was performed using a FACSCalibur (BD Biosciences) equipped with Cell Quest Pro software. Post-processing data analyses were performed with Flowlo software (Tree Star, Inc. Ashland). A Forward Scatter (FSC) vs. Side Scatter (SSC) dot plot was used to gate viable/nucleated cells. At least 10000 events per sample were acquired.

Applying the same staining procedure, FACS-based cell separation was performed on a MoFlow system (Beckman Coulter). Upon antigen-labelling, as described before, the cell suspension was diluted in Accumax (Gibco) supplemented with $0.5 \%$ Ethylenediaminetetraacetic acid (EDTA) (0.5 M pH 8) to reduce re-aggregation of cells over prolonged time. The sorted populations were either used for clonogenic assays or gene expression analysis.

\section{Clonogenic assay}

Upon cell separation, one single cell was deposited into each well of a 96-well plate, containing $200 \mu \mathrm{l}$ cell culture medium (one plate per cell population). Microscopic examination of individual wells ensured single cell plating. After 4 weeks the wells were analyzed for the presence of spheres indicating clonal growth. Subsequently, second and third generations of spheres were generated. The wells from one plate, which contained a sphere that evolved from one cell, were pooled, centrifuged and resuspended in $1 \times$ PBS. The single cell suspension was then again sorted into a 96-well plate with one cell per well, using the viability of the cells as the sorting condition. Cell debris was excluded using a FSC vs. SSC gating. Importantly, to exclude doublets, triplets and small spheres, a FSC vs. pulse width assessment was applied. The clonogenic assay was repeated in 3 independent repetitions. A fraction of cells of each population was preserved for QPCR analyses.

\section{RNA extraction, reverse transcription and real-time quantitative PCR}

Total RNA was isolated using the RNeasy Mini kit (Qiagen) according to the manufacturer's instructions. Total RNA extracts were photometrically quantified with Nanodrop2000c. Reverse transcription (rt) was performed according to manufacturer's protocol using the SuperScript ${ }^{\circledR}$ III Reverse Transcriptase kit (Invitrogen). Complementary-DNA (cDNA) was diluted to a $10 \mathrm{ng} / \mu \mathrm{l}$ working solution and stored at $-20^{\circ} \mathrm{C}$. 
Abundance of transcripts was determined by realtime quantitative PCR on a MyiQ Real-Time PCR Detection System (Bio-Rad Laboratories) based on SYBR Green incorporation (Applied Biosystems). Primers were used at the concentration of $10 \mathrm{pmol}$ (for sequences see supplementary Fig. S1). All relative quantifications were normalized to endogenous housekeeping control ( $\beta$-ACTIN).

The values were automatically determined by the supplied software of the MyiQ Real-Time PCR Detection System (Bio-Rad). For each approach the results were given as mean values \pm standard deviation (SD). All experiments were done in triplicates.

To determine pathway activation levels we tested transcription of the components of stem cell-related signalling cascades. In detail, for WNT/ $\beta$-catenin pathway we quantified important direct downstream target and member of $\beta$-catenin inactivation complex AXIN2 [22]. Furthermore, Jagged1 (JAG1) - an activating ligand of the NOTCH1-receptor - involved in the canonical NOTCH-activity $[14,42]$, and the signalling transducer SMOOTHENED (SMO) as well as downstream-target GLI1 of the Hedgehog-network [11,42], were analyzed. We also included mRNA-expression quantification for YAP1, a key modulator of the recently described Hippo-Yap pathway [36].

\section{Statistical analysis}

All graphs were generated using Sigma Blot; all clonogenicity-data shown are the mean of two independent experiments with error bars indicating the standard deviation (SD). The statistical significances for the clonogenic data were ascertained via Anova test using STATISTICA v5.1 (StatSoft Inc.). Wherever there was a significant main effect, a post-hoc test (NewmanKeuls test) was applied, ${ }^{* *} p \leq 0.01$.

For q-PCR results, means based on the CP valueraw data of three independent repetitions for each gene and condition were compared with Student $t$-test using Statview 5.0 (SAS Institute Inc, USA); error bars = SD, ${ }^{*} p \leq 0.05$.

\section{Results}

\section{Clinical and histopathological presentation}

The GBM10 cell line was established from primary resection tissue of a $6 \mathrm{~cm}$ enhancing cystic mass centred in the right parietal lobe of a 74-year-old Caucasian male. Microscopic examination of the resected tumour revealed a cellular lesion with both astrocytic and primitive/embryonal elements. The astrocytic component was infiltrative and contained regions with large, pleomorphic giant cells and scattered atypical mitotic fig-

\begin{tabular}{|c|c|c|}
\hline Primers & forward & reverse \\
\hline ACTB & 5' CCC AGC ACA ATG AAG ATC AA 3' & 5' CGA TCC ACA CGG AGT ACT TG 3' \\
\hline AXIN2 & 5' AGC CAA AGC GAT CTA CAA AAG G 3' & 5' GGT AGG CAT TTT CCT CCA TCA C 3' \\
\hline PROM1 & 5' CAT CCA CAG ATG CTC CTA AGG C 3' & 5' GCT TTA TGG GAG TCT TGG GTC 3' \\
\hline GFAP & 5' GGC AAA AGC ACC AAA GAC GG 3' & 5' GGC GGC GTT CCA TTT ACA AT 3' \\
\hline GLI1 & 5' GCG CAG ACA CAC TGG CG 3' & 5' GAG GCG TGA GTA TGA CTT CCG 3' \\
\hline JAG1 & 5' GAA TGG CAA CAA AAC TTG CAT 3' & 5' AGC CTT GTC GGC AAA TAG C 3' \\
\hline MSI1 & 5' GGA CTC AGT TGG CAG ACT ACG 3' & 5' CTG GTC CAT GAA AGT GAC GAA 3' \\
\hline NANOG & 5' TGA TTT GTG GGC CTG AAG AAA A 3' & 5' GAG GCA TCT CAG CAG AAG ACA 3' \\
\hline NES & 5' GGC GCA CCT CAA GAT GTC C 3' & 5' CTT GGG GTC CTG AAA GCT G 3' \\
\hline OLIG2 & 5' CCA GAG CCC GAT GAC CTT TTT 3' & 5' CAC TGC CTC CTA GCT TGT CC 3' \\
\hline SMO & 5' GAG ACT CTG TCC TGC GTC ATC A 3' & 5' AGG CAT AGG TGA GGA CCA CAA 3' \\
\hline $\mathrm{SO} 2$ & 5' TGG ACA GTT ACG CGC ACA T 3' & 5' CGA GTA GGA CAT GCT GTA GGT 3' \\
\hline YAP & 5' ATG TAC CTC TGC CAG CAG GTT 3' & 5' TTC ATC TGG GAC AGC ATG G 3' \\
\hline
\end{tabular}

Supplementary Fig. S1 Primer sequences applied in this work 

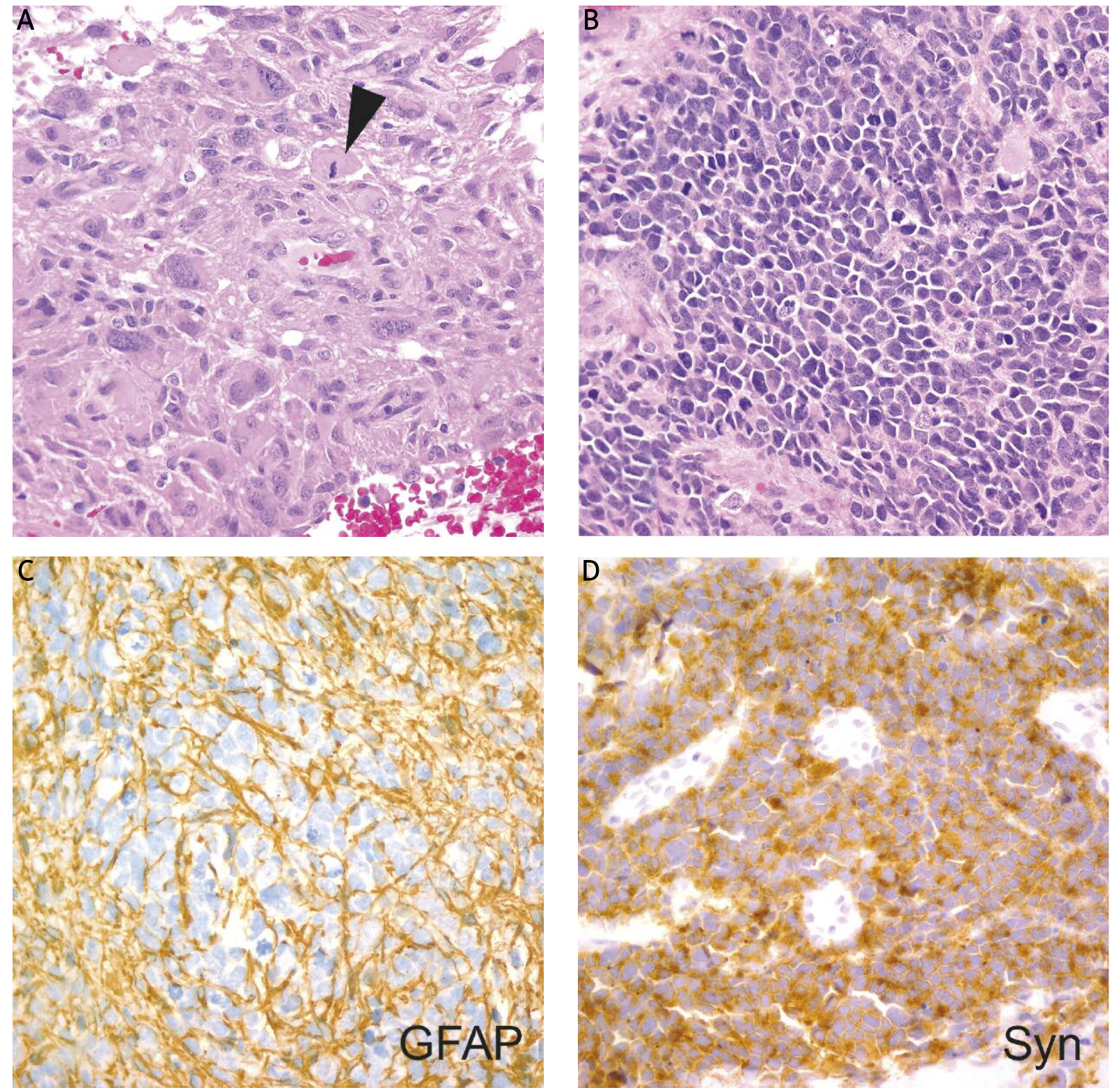

Fig. 1. Histopathology of the primary tumour from which GBM10 neurospheres were derived. A) In some areas the tumour was comprised of glial-appearing gemistocytic and giant cells similar to those seen in most GBMs. Mitotic figures were also noted (arrow). B) In other areas, the tumour had an embryonal appearance with tightly packed round to oval cells. C) Many regions of the tumour were GFAP immunoreactive. D) The PNET-like component also expressed the neuronal marker synaptophysin. All panels 400× original magnification.

ures (Fig. 1A, arrow). The PNET-like component was comprised of tightly packed small to medium-sized cells in sheets with significant moulding and numerous mitotic figures (Fig. 1B). Both necrosis and endothelial vascular proliferation were also present in the lesion.
Immunohistochemical analysis using GFAP confirmed glial differentiation in much of the tumour (Fig. 1C), with strong expression of the neuronal marker synaptophysin in the PNET-like component (Fig. 1D). 


\begin{tabular}{lcc} 
A & HSR-GBM1 & GBM10 \\
\hline CD133 [\%] & 25.47 & 46.38 \\
\hline CD15 [\%] & 95.94 & 66.22 \\
\hline
\end{tabular}
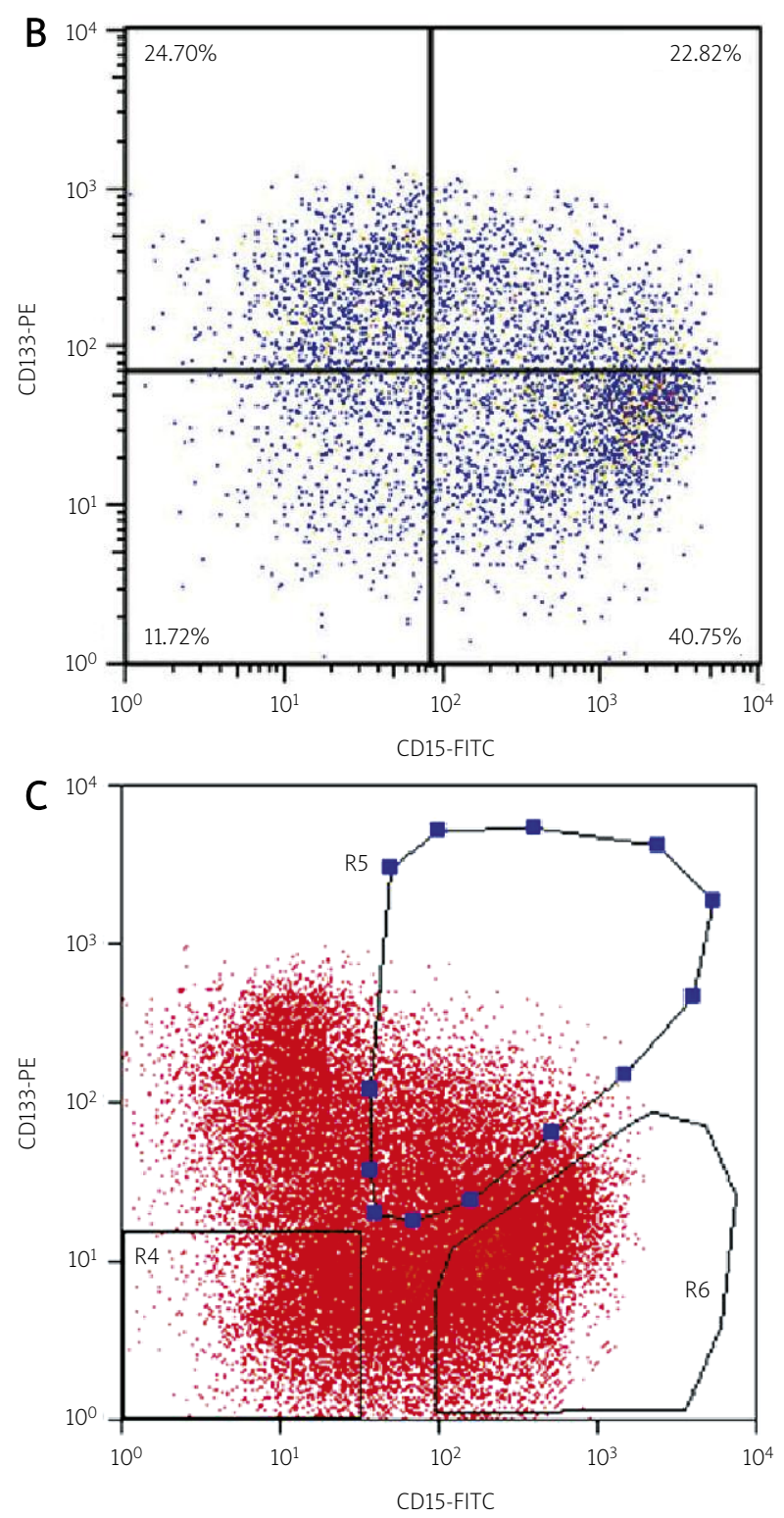

Fig. 2. Cell surface marker expression of GBM10 (GBM-PNET) and HSR-GBM1 (GBM), mean values of three independent repetitions plus SD (A). Coexpression of CD133 with CD15 revealed distinct subpopulations (B). Gates set in the GBM10-FACS sorts: dot plot with CD15-FITC vs. CD133-PE: double negative, $(--)$, gate R4; single positive, single negative, $(-+)$, gate R6; double positive, $(++)$, gate R5 (C).

\section{GBM (HSR-GBM1) and GBM-PNET (GBM10) cell lines express putative BTSC cell surface markers CD133 and CD15}

Both tested cell lines express significant amounts of neural stem cell (NSC) and putative BTSC markers CD133 (25\% for HSR-GBM1, 46\% for GBM10) and CD15 (95\% for HSR-GBM1, 66\% for GBM10) after in vitro propagation in free floating conditions (for results of cell surface marker expression analysis see Fig. 2A). To examine whether the CD15 is co-expressed with CD133, double staining was performed. This approach revealed the presence of well-defined double positive subpopulations (Fig. 2B). Based on these data and on the findings of other groups $[25,44,45]$ we investigated functional and genetic differences of the distinct cell populations based on their cell surface expression pattern. For further analyses we separated three subpopulation using FACS (gating is shown in Fig. 2C). Besides cells negative for both markers (double negative population (- - ), gate $\mathrm{R} 4)$, a population negative for CD133 and positive for CD15 $(-+)$, gate R6, as well as a population positive for both surface markers (double positive population, $(++)$, gate R5) were sorted and analyzed.

\section{CD133+/CD15+ and CD133-/CD15- cells display high clonogenic potential in GBM-PNET neurospheres}

A cardinal property of BTSCS is the capability of self-renewal and extensive proliferation. These capacities can be demonstrated using in vitro clonogenic sphere formation assays starting from single cells. The sphere formation capacity of the three sorted populations $(--,-+,++)$ was investigated for three generations as described above. Macroscopic observation revealed that the neurospheres evolving from a single cell were heterogenic concerning their size and structure, independent of the sorted fraction (Fig. 3). However, quantification of the spheres showed significant differences between examined separated subpopulations only in GBM-PNET-derived cell culture (Fig. 4A) but not in HSR-GBM1 (Fig. 4B). The $(-+)$ cells of GBM10 were characterized by significantly lower clonogenic capacity than $(++)$ and $(--)$ cells in all examined sphere generations. Interestingly, the double positive cell population with relatively low clonogenic potential in the first generation showed a remarkable increase of sphere 

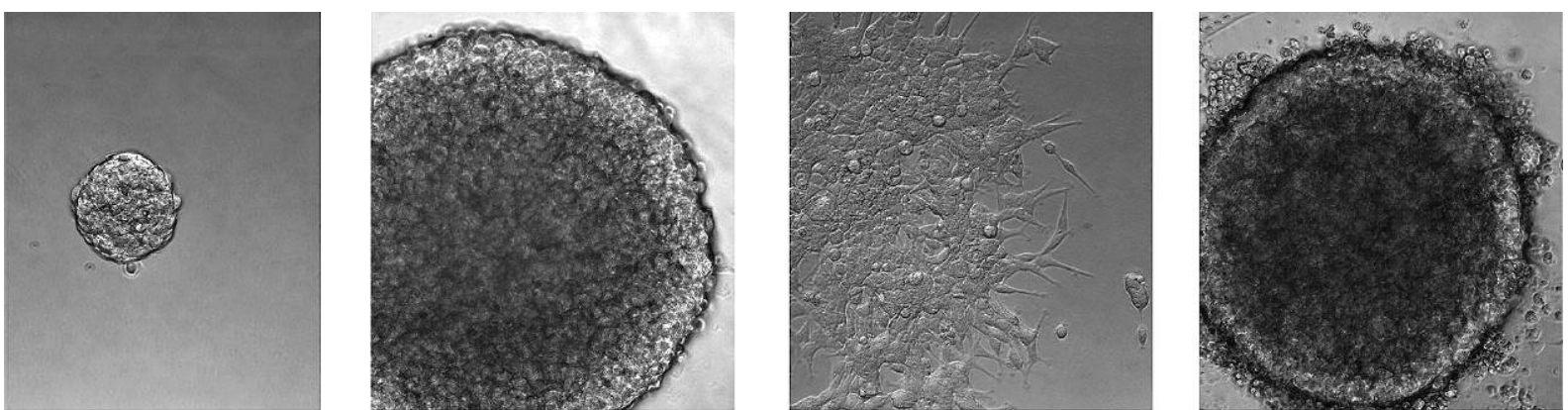

Fig. 3. Representative tumour spheres generated in the clonogenic assay after single cell plating. Size and structure are heterogeneous independent of the origin of the sorted cell population they were generated from both GBM-PNET and GBM. All 20x magnification, light microscopy.

A

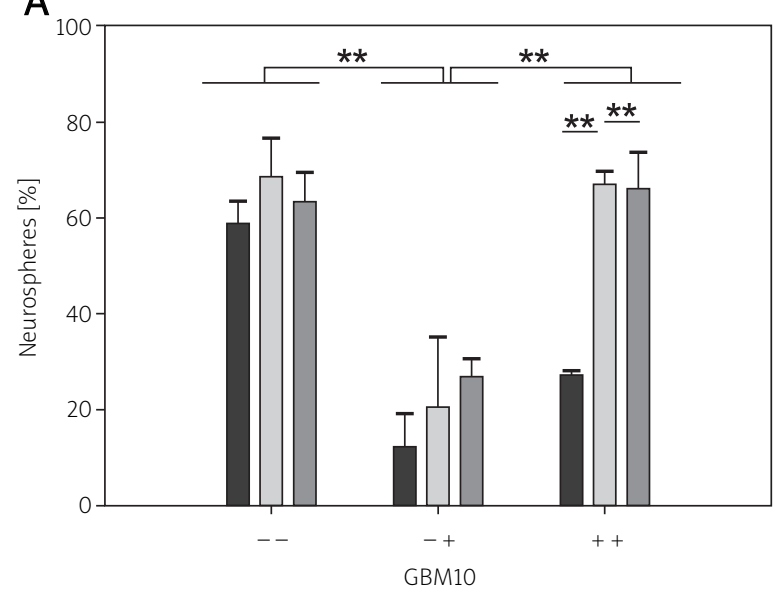

B

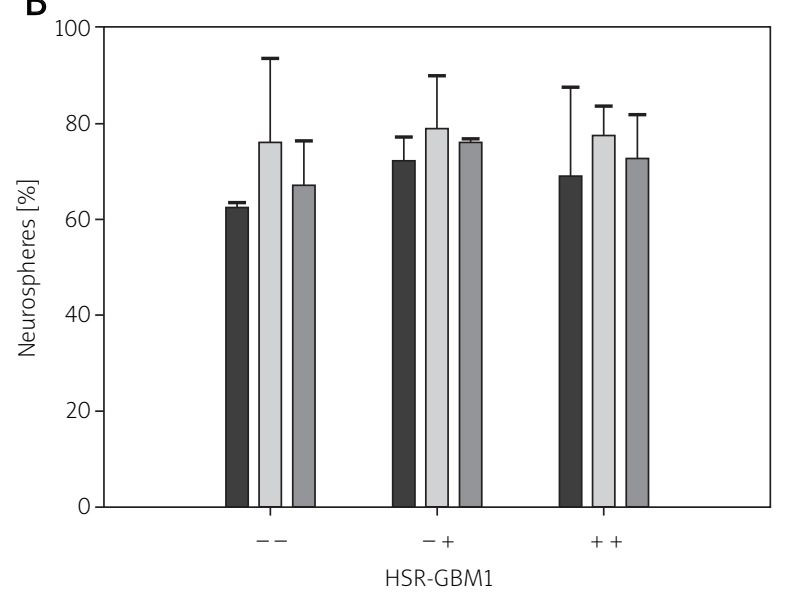

$\square$ G1 $\square$ G2 $\square$ G3

Fig. 4. Sphere formation capacity of three sorted cell populations $(++,-+,--)$ of three generations (G1, G2, G3) for GBM-PNET line (GBM10) and GBM line (HSR-GBM1). For GBM10, significant increased clonogenicity in $(++)$ and $(--)$ compared to $(-+)$ cell population, where $(++)$ population increased tumour formation potential from G1 to G2/G3 (A); In contrast, HSR-GBM1 did not show any significant differences in in vitro clonogenicity independent of generation and cell surface marker composition (B); ${ }^{* *} p \leq 0.01$.

formation in the second and third generation (Fig. 4A). In contrast, the sorted subpopulations derived from GBM cell line lacking PNET component (HSR-GBM1) showed no differences in clonogenic capacity throughout the whole experiment. These data demonstrate unequivocally that the sorted cells derived from GBM-PNET represent distinct subpopulations not only in terms of the surface antigen composition but also regarding their in vitro tumour formation capacity.

\section{Expression analysis of stem cell-related genes}

Afterwards, we determined the stem-like genotype of the sorted subpopulations using rt qPCR-based ana- lysis of a panel of stem cell-related genes. Beside PROMININ1 (PROM1), encoding for CD133, we analyzed established neural stem cell markers MUSASHI1 (MSI1), NANOG, NESTIN, SOX2 and OLIG2. Glial differentiation was assessed by GFAP transcription levels (Fig. 5A).

Analysis of PROM1 expression confirmed successful sorting (3.6 $\mathrm{x}$ increased in ++ ). Interestingly, in GBM-PNET cell line, CD133-/CD15 ${ }^{+}$fraction showed significantly decreased transcription of stem cell-related genes as compared to $\mathrm{CD} 133^{+} / \mathrm{CD}_{15}{ }^{+}$and $\mathrm{CD} 133^{-} / \mathrm{CD} 15^{-}$ cell populations. Compared to $(--)$ cells, the $(-+)$ subgroup displayed about $65-75 \%$ expression for MSI1, SOX2, NANOG and about 40\% expression for OLIG2. 

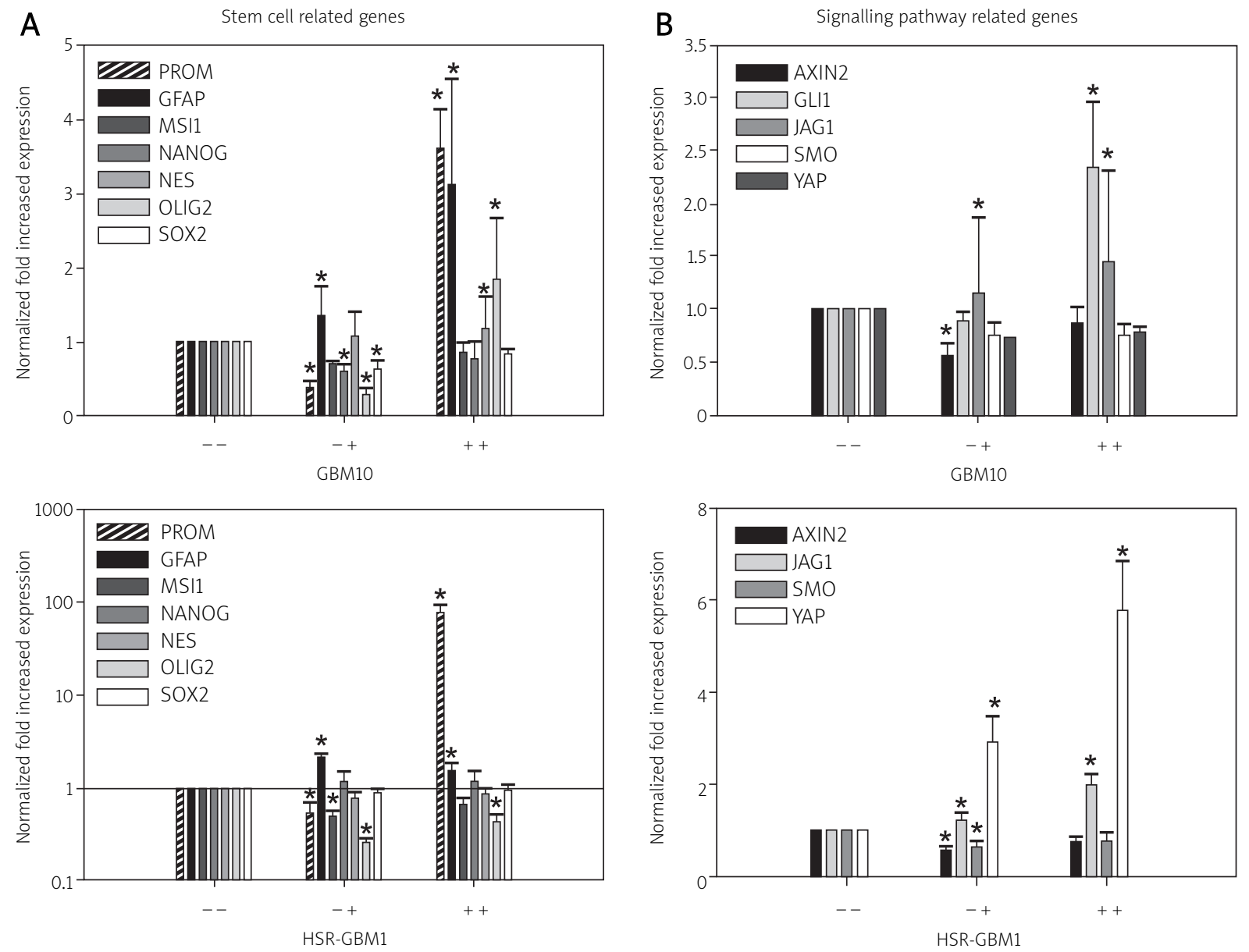

Fig. 5. mRNA quantification of stem cell and signalling-pathway related genes in the three subpopulations for GBM-PNET cell line (GBM10) and GBM cell line (HSR-GBM1). GBM10 $(-+)$ population shows significant reduced stem cell gene expression compared to (- -)- and (+ +) fraction. In contrast, HSR-GBM1 does not show any strong variations in the analyzed stem cell markers in any of the three subfractions (Strong PROM1 overexpression in $(++)$ in both cell lines proofs successful sorting (A). Interestingly, in case of PNET-GBM line poor stem cell transcription profile in $(-+)$ overlaps with reduced mRNA levels of important downstream target genes for WNT/ $\beta$-catenin, NOTCH-, Hedgehog- and Hippo-pathway. In contrast, for HSR-GBM1 $\mathrm{NOTCH}$ - and Hedgehog-activity increases from $(--)$ to $(-+)$ to $(++)(\mathrm{B}) .{ }^{*} p \leq 0.05$.

In contrast, HSR-GBM1 subpopulations did not show strong transcription differences and especially $(-+)$ cells displayed no significant reduction in stem cell-related mRNA levels (Fig. 5A, overexpression of PROM1 in $(++)$ cells proofs successful FACS sorting).

\section{Analysis of signalling pathway related genes}

Differential stem-cell signature and tumorigenicity often involves altered signalling pathways, important for stem-cell maintenance and proliferation.
Therefore, we tested our sorted cell fractions for their individual pathway activation level. We analyzed the expression of established down-stream target genes for the WNT/ $\beta$-catenin pathway (AXIN2 [22]), Notchpathway (JAG1 [14,42], Hedgehog-pathway (GLI1, SMO $[11,42]$, as well as the recently described Hippo pathway (YAP1 [36]).

In the GBM10 cell line, the $(++)$-population was characterized by significant up-regulation of GLI1 and JAG1 as compared to the double negative population (Fig. 5B). Interestingly, the analysis of all target gene 


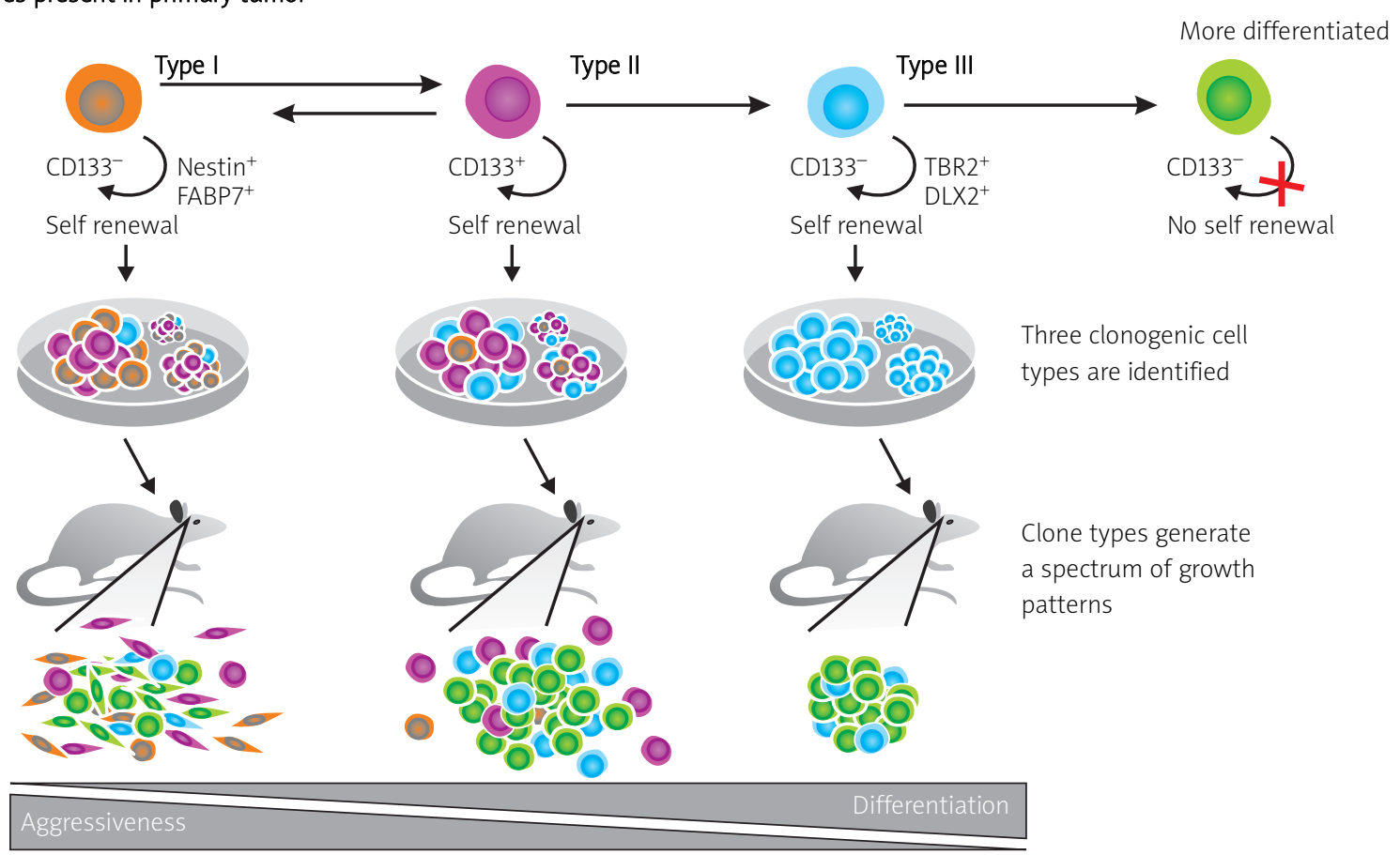

Fig. 6. Lineage Hierarchy Model of Type I, II, and III cells (comprising CD133- and CD133+ phenotype) in GBMs. Type I to Type III cells decrease in tumorigenic potential, however all subtypes remain tumorigenic, except fully differentiated $4^{\text {th }}$ type of CD133- cells, figure taken from Chen et al. Cancer Cell 2010 [10], with permission from Elsevier Limited.

transcripts showed significantly decreased pathway activity in the less clonogenic CD133-/CD15 -population, with about $80 \%$ lower expression levels of YAP1 and SMO as well as $55 \%$ diminution of AXIN2 transcription as compared to $\mathrm{CD} 133^{-} / \mathrm{CD} 15^{-}$subpopulation.

In contrast, the $(-+)$ and even more the $(++)$ fraction of the GBM cell line (HSR-GBM1) displayed significant overexpression of transcripts belonging to the Hippo- and NOTCH-signalling cascades (Fig. 5B).

\section{Discussion}

In this work we describe the isolation and characterization of distinct cell subpopulations from an in vitro propagated GBM-PNET based on the expression of defined cell surface markers. We used a combination of markers related to tumour stem cell phenotype including CD133 (PROMININ1), which has widely been accepted as a bona fide brain tumour stem cell marker with clinical prognostic value. Interestingly, recent immunohistological detection of CD133/Ki76 positive cells in atypical meningiomas suggests the significance of this marker also in the biology of other intracranial neoplasia [2]. Moreover, other stem cell-related markers such as CD15- being expressed in several brain tumours $[40,49]$ and CD29 $[18,25]$ and Integrin alpha 6 - highly expressed in GBMs compared to non-neoplastic brain tissue $[13,16]$ - were investigated. By analyzing the presence of CD133 and CD15 antigens on the surface of the cells, we were able to distinguish three distinct subpopulations referred to as (- - ) (CD133/ CD15 $),(-+)\left(C D 133^{-} / \mathrm{CD} 5^{+}\right)$and $(++)\left(\mathrm{CD} 133^{+} / \mathrm{CD} 5^{+}\right)$ cells as putative BTSC-immunophenotypes.

To test the cardinal feature of the tumour stem cell - the ability of clonal growth - we performed single cell in vitro clonogenicity formation assays over three generations. Interestingly, in GBM-PNET (GBM10), but not in a GBM cell line without PNET foci (HSR-GBM1), $(++)$ and $(--)$ subpopulations showed significantly increased numbers in sphere formation as compared to the $(-+)$ fraction. To our surprise, in the first generation of the GBM-PNET cell line (low passage $\leq 15$ ) after sorting, the (--) population was the most clonogenic and not, as expected, the cell fraction positive for all three enrichment markers. However, $\mathrm{CD}_{133^{+}} /$ $\mathrm{CD} 5^{+}$cells increased their in vitro clonogenicity in the 
second and third generation, whereas the $\mathrm{CD}_{133}{ }^{-}$/ $\mathrm{CD}_{15}{ }^{+}$population remained the least clonogenic throughout the whole experiment.

These findings correspond to tumour stem cell lineage hierarchy proposed by Chen et al. [10]. This model postulates the existence of three types of self-renewing tumour-initiating cells with diverse phenotypic characteristics in GBMs (Fig. 6). Type I cells (CD133-), which are able to give rise to aggressive tumours that consist both of $\mathrm{CD}_{133^{+}}$and $\mathrm{CD}_{133^{-}}$cells; the Type II cells which are positive for CD133 and generate rapidly growing, invasive grafts that comprise also a mixture of CD133+ and CD133- cells and Type III cells (CD133-) which form confined tumour masses growing slowly. In addition, the existence of a fourth more differentiated $\mathrm{CD}_{133^{-}}$cell population with non-tumorigenic properties and limited proliferation capacity under neurosphere conditions was proposed. According to the model, Type I, II, and III cells are lineally related and represent discrete stages of differentiation. Type I cells are the least and type III cells the most differentiated, whereas type II cells represent an intermediate stage.

Applying this model to our study, the double negative GBM-PNET cells correlate to the Type I cells since they show the highest clonogenicity and are negative for CD133 surface marker expression. Of note, testing the three subpopulations derived from in vitro cultures of a GBM cell line without a PNET-like component revealed no significant differences in their sphere formation capacity.

Furthermore, gene expression of GBM-PNET cell line revealed increased stem cell signature in (- -)-population going along with the proposed model of a CD133negative BTCS fraction. Based on this concept, the double positive population would be then made up of Type II cells, since they are both clonogenic and positive for CD133 expression. The $(-+)$-population could be categorized as belonging to the fourth population with no self-renewal capacity since it is negative for CD133 and shows only minimal clonogenic potential. In concordance to these findings we observed an upregulation of stem cell related genes (PROM1, MSI1, NANOG, NESTIN and SOX2) in the populations that appeared to be more clonogenic $(--,++)$ and their lower transcription in less clonogenic fraction $(-+)$.

In addition, the status of differentiation was assessed by analyzing lineage specific markers GFAP, encoding for the glial fibrillary acidic protein, a marker for astroglial lineage [41] and OLIG2 - a transcription factor that induces the differentiation of neural stem cells [1]. Altogether these data imply that for the GBMPNET cell line $\mathrm{CD} 133^{-} / \mathrm{CD} 15^{+}$subpopulation fails to show stem-like cell properties, both at the functional and gene expression level. Moreover, our results show an upregulation of GFAP and OLIG2 in the $(-+)$ as well as the $(++)$-population in GBM10. These differential transcription levels of GFAP and OLIG2 add to the proposed model of induced differentiation from $(--)$ to $(++)$ and $(-+)$ cells. Interestingly, cell separation from classical GBM lines did not show significant increase of stem cell marker transcription in the tested subpopulations.

Stem-like cell properties are regulated by important developmental signalling pathways including WNT/ $\beta$-catenin [23,34], Sonic-Hedgehog (SHH) [8], Notch [17] and Hippo [47] pathway. However, deregulation of these powerful networks implicated in numerous biological processes is a major source of cancerous malformations (i.e. [12,30,32,43]). To address potential pathway over-activation in the aggressive stem-like enriched cell fraction of tested cell lines, we determined the individual pathway activity by quantifying direct down-stream target gene expression of different signalling cascades. Again, in GBM-PNETderived cell line within the sorted (- - ) fraction, AXIN2 indicating the activation of canonical WNT/ $\beta$-catenin pathway appeared to be significantly elevated as compared to the $(++)$ and even more to the $(-+)$ fraction. WNT/ $\beta$-catenin activation has recently been reported by our group to be directly involved in regulating the BTSC phenotype and increasing GBM malignancy [22]. Interestingly, YAP1 - a marker for Hippo-pathway activation being reported to promote the growth of GBM cell lines in vitro and associated with aggressive molecular subsets of GBM [36], showed a similar expression profile, with transcript decrease from (--) over $(++)$ to $(-+)$ cells. The $\mathrm{CD} 133^{-} / \mathrm{CD} 5^{+}$cell fraction showed additionally a significant reduction of JAG1 and GLI1 expression suggesting an inhibited NOTCH and SHH pathway activation pattern.

HSR-GBM1 shows a continual increase of transcription levels of JAG1 and YAP from $(--)$ to $(-+)$ to $(++)$ indicating a possible relationship of NOTCH- and Hippopathway activation levels with putative BTSC-marker CD133/PROM1. Of note, these phenomena in classical in vitro propagated GBM cell lines have already been reported $[14,15,36,42]$.

In conclusion, our study reports the identification of a tumour initiating cell population based on its cell 
surface expression pattern in a unique GBM-PNETderived cell culture. A combinatory code of CD133/CD15 enabled the separation of three different subclasses of cells with different genetic background regarding stem cell identity and signalling pathway activation. However, the genetic and functional data collected from classical GBM line failed to convincingly show these remarkable differences. Therefore, due to the complex heterogeneity of GBMs, it is unlikely that the expression of a single marker, like CD133, could be sufficient for unequivocal identification of BTSCs in all subgroups of $G B M s$, as previously suggested $[6,21,35]$.

Furthermore, current results demonstrate the existence of two different populations within GBM-PNETderived cell line negative for CD133 including highly aggressive, dedifferentiated and clonogenic active cells $(--)$ as well as their better differentiated, less malignant counterpart $(-+)$. It is likely that different subidentities of malignant gliomas, including gliosarcomas [27], pro-neural, neural, classical or worst prognostic mesenchymal GBMs $[33,38]$ as well as GBM-PNET have different cell surface marker codes for identification of their individual tumour-initiating cell population(s). In summary, this work contributes to better understanding of the heterogeneity of in vitro propagated glioblastoma-derived cells focusing on tumours with PNET-like components, both regarding functional as well as molecular aspects potentially leading to improved diagnosis of stem-like cell population.

\section{References}

1. Ahn SM, Byun K, Kim D, Lee K, Yoo JS, Kim SU, Jho EH, Simpson RJ, Lee B. Olig2-induced neural stem cell differentiation involves downregulation of Wnt signaling and induction of Dickkopf-1 expression. PloS One 2008; 3: e3917.

2. Albayrak BS, Ismailoglu O, Tanriover G, Cetinalp EN, Demir N. The double immunostaining of CD133 and Ki-67 favours a sig nificant co-localization pattern in fibroblastic subtype of menin giomas. Neurol Neurochir Pol 2011; 45: 467-473.

3. Bao S, Wu Q, McLendon RE, Hao Y, Shi Q, Hjelmeland AB, Dewhirst MW, Bigner DD, Rich JN. Glioma stem cells promote radioresistance by preferential activation of the DNA damage response. Nature 2006; 444: 756-760.

4. Bar EE, Chaudhry A, Lin A, Fan X, Schreck K, Matsui W, Piccirillo S, Vescovi AL, DiMeco F, Olivi A, Eberhart CG. Cyclopamine-mediated hedgehog pathway inhibition depletes stem-like cancer cells in glioblastoma. Stem Cells 2007; 25: 2524-2533.

5. Bar EE, Lin A, Mahairaki V, Matsui W, Eberhart CG. Hypoxia increases the expression of stem-cell markers and promotes clonogenicity in glioblastoma neurospheres. Am J Pathol 2010; 177: 1491-1502.

6. Beier D, Hau P, Proescholdt M, Lohmeier A, Wischhusen J, Oefner PJ, Aigner L, Brawanski A, Bogdahn U, Beier CP. CD133+ and
CD133- Glioblastoma-Derived Cancer Stem Cells Show Differential Growth Characteristics and Molecular Profiles. Cancer Res 2007; 67: 4010-4015

7. Bleau AM, Huse JT, Holland EC. The ABCG2 resistance network of glioblastoma. Cell Cycle 2009; 8: 2936-2944.

8. Chambers SM, Studer L. Cell fate plug and play: direct reprogramming and induced pluripotency. Cell 2011; 145: 827-830.

9. Chen J, McKay RM, Parada LF. Malignant glioma: lessons from genomics, mouse models, and stem cells. Cell 2012; 149: 36-47.

10. Chen R, Nishimura MC, Bumbaca SM, Kharbanda S, Forrest WF, Kasman IM, Greve JM, Soriano RH, Gilmour LL, Rivers CS, Modrusan Z, Nacu S, Guerrero S, Edgar KA, Wallin JJ, Lamszus K, Westphal M, Heim S, James CD, VandenBerg SR, Costello JF, Moorefield S, Cowdrey CJ, Prados M, Phillips HS et al. 2010. A hierarchy of self-renewing tumor-initiating cell types in glioblastoma. Cancer Cell 2010; 17: 362-375.

11. Clement V, Sanchez P, de Tribolet N, Radovanovic I, Ruiz i Altaba A. HEDGEHOG-GLI1 signaling regulates human glioma growth, cancer stem cell self-renewal, and tumorigenicity. Curr Biol 2007; 17: 165-172.

12. Clevers H. Wnt/beta-catenin signaling in development and disease. Cell 2006; 127: 469-480.

13. Delamarre E, Taboubi S, Mathieu S, Bérenguer C, Rigot V, Lissitzky JC, Figarella-Branger D, Ouafik L, Luis J. Expression of integrin alpha6beta1 enhances tumorigenesis in glioma cells. Am J Pathol 2009; 175: 844-855.

14. Fan X, Khaki L, Zhu TS, Soules ME, Talsma CE, Gul N, Koh C, Zhang J, Li YM, Maciaczyk J, Nikkhah G, Dimeco F, Piccirillo S, Vescovi AL, Eberhart CG. NOTCH pathway blockade depletes CD133positive glioblastoma cells and inhibits growth of tumor neurospheres and xenografts. Stem Cells 2010; 28: 5-16.

15. Fan X, Matsui W, Khaki L, Stearns D, Chun J, Li Y-M, Eberhart CG. Notch pathway inhibition depletes stem-like cells and blocks engraftment in embryonal brain tumors. Cancer Res 2006; 66: 7445-7452.

16. Gingras MC, Roussel E, Bruner JM, Branch CD, Moser RP. Comparison of cell adhesion molecule expression between glioblastoma multiforme and autologous normal brain tissue. J Neuroimmunol 1995; 57: 143-153.

17. Gustafsson MV, Zheng X, Pereira T, Gradin K, Jin S, Lundkvist J, Ruas JL, Poellinger L, Lendah, U, Bondesson M. Hypoxia requires notch signaling to maintain the undifferentiated cell state. Dev Cell 2005; 9: 617-628.

18. Hall PE, Lathia JD, Miller NGA, Caldwell MA, Ffrench-Constant C. Integrins are markers of human neural stem cells. Stem Cells 2006; 24: 2078-2084

19. Ishizawa K, Kan-nuki S, Kumaga H, Komori T, Hirose T. Lipomatous primitive neuroectodermal tumor with a glioblastoma component: a case report. Acta neuropathol 2002; 103: 193-198.

20. Jamal M, Rath BH, Tsang PS, Camphausen K, Tofilon PJ. The brain microenvironment preferentially enhances the radioresistance of CD133(+) glioblastoma stem-like cells. Neoplasia 2012; 14: 150-158.

21. Joo KM, Kim SY, Jin X, Song SY, Kong DS, Lee Jl, Jeon JW, Kim MH, Kang BG, Jung Y, Jin J, Hong SC, Park WY, Lee DS, Kim H, Nam DH. Clinical and biological implications of CD133-positive and CD133negative cells in glioblastomas. Lab Invest 2008; 88: 808-815. 
22. Kahlert U, Maciaczyk D, Doostkam S, Orr BA, Simons B, Bogiel T, Reithmeier T, Prinz M, Schubert J, Niedermann G, Brabletz T, Eberhart CG, Nikkhah G, Maciaczyk J. Activation of canonical WNT/ $\beta$-catenin signaling enhances in vitro motility of glioblastoma cells by activation of ZEB1 and other activators of epithelial-to-mesenchymal transition. Cancer Lett 2012; 325: 42-53.

23. Kalani MYS, Cheshier SH, Cord BJ, Bababeygy SR, Vogel H, Weissman IL, Palmer TD, Nusse R. Wnt-mediated self-renewal of neural stem/progenitor cells. Proc Nat Acad Sci USA 2008; 105: 16970-16975.

24. Kelly JJP, Stechishin O, Chojnacki A, Lun X, Sun B, Senger DL, Forsyth P, Auer RN, Dunn JF, Cairncross JG, Parney IF, Weiss S. Proliferation of human glioblastoma stem cells occurs independently of exogenous mitogens. Stem Cells 2009; 27: 1722-1733.

25. Lathia JD, Gallagher J, Heddleston JM, Wang J, Eyler CE, Macswords J, Wu Q, Vasanji A, McLendon RE, Hjelmeland AB, Rich JN. Integrin alpha 6 regulates glioblastoma stem cells. Cell stem cell 2010; 6: 421-432.

26. Lawrence YR, Mishra MV, Werner-Wasik M, Andrews DW, Showalter TN, Glass J, Shen X, Symon Z, Dicker AP. Improving prognosis of glioblastoma in the 21st century: Who has benefited most? Cancer 2011; 118: 4228-4234.

27. Louis DN, Ohgaki H, Wiestler OD, Cavenee WK, Burger PC, Jouvet A, Scheithauer BW, Kleihues P. The 2007 WHO classification of tumours of the central nervous system. Acta Neuropathol 2007; 114: 97-109.

28. Maciaczyk J, Singec I, Maciaczyk D, Klein A, Nikkhah G. Restricted spontaneous in vitro differentiation and region-specific migration of long-term expanded fetal human neural precursor cells after transplantation into the adult rat brain. Stem Cells Dev 2009; 18: 1043-1058.

29. McLendon RE, Provenzale J. Glioneuronal tumors of the central nervous system. Brain Tumor Pathol 2002; 19: 51-58.

30. Merchant AA, Matsui W. Targeting Hedgehog - a cancer stem cell pathway. Clin Cancer Res 2010; 16: 3130-3140.

31. Mizrak D, Brittan M, Alison MR. CD133: molecule of the moment. J Pathol 2008; 214: 3-9.

32. Morton JP, Lewis BC. Shh signaling and pancreatic cancer: implications for therapy? Cell Cycle 2007; 6: 1553-1557.

33. Noushmehr H,Weisenberger DJ, Diefes K, Phillips HS, Pujara K, Berman BP, Pan F, Pelloski CE, Sulman EP, Bhat KP, Verhaak RG, Hoadley KA, Hayes DN, Perou CM, Schmidt HK, Ding L, Wilson RK, Van Den Berg D, Shen H, Bengtsson H, Neuvial P, Cope LM, Buckley J, Herman JG, Baylin SB, Laird PW, Aldape K; Cancer Genome Atlas Research Network. Identification of a CpG island methylator phenotype that defines a distinct subgroup of glioma. Cancer Cell 2010; 17: 510-522.

34. Nusse R. Wnt signaling and stem cell control. Cell Res 2008; 18 : 523-527.

35. Ogden AT, Waziri AE, Lochhead RA, Fusco D, Lopez K, Ellis JA, Kang J, Assanah M, McKhann GM, Sisti MB, McCormick PC, Canoll P, Bruce JN. Identification of A2B5+CD133- tumor-initiating cells in adult human gliomas. Neurosurgery 2008; 62: 505-515.

36. Orr BA, Bai H, Odia Y, Jain D, Anders RA, Eberhart CG. Yes-associated protein 1 is widely expressed in human brain tumors and promotes glioblastoma growth. J Neuropathol Exp Neurol 2011; 70: 568-577.
37. Perry A, Miller CR, Gujrati M, Scheithauer BW, Zambrano SC, Jost SC, Raghavan R, Qian J, Cochran EJ, Huse JT, Holland EC, Burger PC, Rosenblum MK. Malignant gliomas with primitive neuroectodermal tumor-like components: a clinicopathologic and genetic study of 53 cases. Brain Pathol 2009; 19: 81-90.

38. Phillips HS, Kharbanda S, Chen R, Forrest WF, Soriano RH, Wu TD, Misra A, Nigro JM, Colman H, Soroceanu L, Williams PM, Modrusan Z, Feuerstein BG, Aldape K. Molecular subclasses of high-grade glioma predict prognosis, delineate a pattern of disease progression, and resemble stages in neurogenesis. Cancer Cell 2006; 9: 157-173.

39. Pruszak J, Ludwig W, Blak A, Alavian K, Isacson O. CD15, CD24, and CD29 define a surface biomarker code for neural lineage differentiation of stem cells. Stem Cells 2009; 27: 2928-2940.

40. Read T-A, Fogarty MP, Markant SL, McLendon RE, Wei Z, Ellison DW, Febbo PG, Wechsler-Reya RJ. Identification of CD15 as a marker for tumor-propagating cells in a mouse model of medulloblastoma. Cancer Cell 2009; 15: 135-147.

41. Reeves SA, Helman LJ, Allison A, Israel MA. Molecular cloning and primary structure of human glial fibrillary acidic protein. Proc Nat Acad Sci USA 1989; 86: 5178-5182.

42. Schreck KC, Taylo, P, Marchionni L, Gopalakrishnan V, Bar EE, Gaiano N, Eberhart CG. The Notch target Hes1 directly modulates Gli1 expression and Hedgehog signaling: a potential mechanism of therapeutic resistance. Clin Cancer Res 2010; 16: 6060-6070.

43. Sethi N, Kang Y. Notch signalling in cancer progression and bone metastasis. Br J Cancer 2011; 105: 1805-1810.

44. Singh SK, Hawkins C, Clarke ID, Squire JA, Bayani J, Hide T, Henkelman RM, Cusimano MD, Dirks PB. Identification of human brain tumour initiating cells. Nature 2004; 432: 396-401.

45. Son MJ, Woolard K, Nam D-H, Lee J, Fine HA. SSEA-1 is an enrichment marker for tumor-initiating cells in human glioblastoma. Cell Stem Cell 2009; 4: 440-452.

46. Uchida N, Buck DW, He D, Reitsma MJ, Masek M, Phan TV, Tsukamoto AS, Gage FH, Weissman IL. Direct isolation of human central nervous system stem cells. Proc Nat Acad Sci USA 2000; 97 : 14720-14725.

47. Varelas X, Miller BW, Sopko R, Song S, Gregorieff A, Fellouse FA, Sakuma R, Pawson T, Hunziker W, McNeill H, Wrana JL, Attisano L. The Hippo pathway regulates Wnt/beta-catenin signaling. Dev Cell 2010; 18: 579-591.

48. Vescovi AL, Galli R, Reynolds BA. Brain tumour stem cells. Nature Rev Cancer 2006; 6: 425-436.

49. Ward RJ, Lee L, Graham K, Satkunendran T, Yoshikawa K, Ling E, Harper L, Austin R, Nieuwenhuis E, Clarke ID, Hui C-C, Dirks PB. Multipotent CD15+ cancer stem cells in patched-1-deficient mouse medulloblastoma. Cancer Res 2009; 69: 4682-4690.

50. Wolańczyk M, Hułas-Bigoszewska K, Witusik-Perkowska M, Papierz W, Jaskólski D, Liberski PP, Rieske P. Imperfect oligodendrocytic and neuronal differentiation of glioblastoma cells. Folia Neuropathol 2010; 48: 27-34. 